\title{
AS RELAÇÕES REPRODUTORAS NOS ESPAÇOS DE ENSINO JURÍDICO
}

\author{
Augusto Jobim do Amaral ${ }^{1}$ \\ Fernanda Martins ${ }^{2}$
}

\begin{abstract}
Resumo
As reflexões ora desenvolvidas buscam evidenciar as relações de poder e a dominação como mecanismos de reprodução social nos âmbitos de ensino. Ainda, apresenta-se possível postura para a prática educativa que questione os antigos métodos de ensino a partir de suas bases epistemológicas. Assim, a partir das teorias de Bourdieu sobre a reprodução de estratificações sociais com base na perpetuação de um ensino impositivo tanto no ambiente familiar quanto escolar, busca-se elaborar uma conexão deste "modelo reprodutor" sugerido pelo autor com as teorias foucaultianas de governabilidade e disciplina desenvolvidos pelas instituições sociais e políticas, presente entre elas o próprio ensino. Julga-se, dessa forma, como condição de possibilidade para a adoção dessa nova postura o respeito ao Outro, através da ética da alteridade, e, no contexto do debate acerca da falência dos monólogos acadêmicos.
\end{abstract}

Palavras-chave: Ensino, reprodução, dominação.

\section{INTRODUÇÃO}

As reflexões que serão desenvolvidas neste texto buscam evidenciar as relações de poder e a dominação como mecanismos de reprodução social nos âmbitos de ensino. Ainda pretende apresentar uma possível postura para a prática educativa que questione os antigos métodos de ensino a partir de suas bases epistemológicas.

Julga-se como condição de possibilidade para a adoção dessa nova postura o respeito ao Outro, através da ética da alteridade, e, no contexto do debate acerca da falência dos monólogos acadêmicos.

A partir das teorias de Bourdieu sobre a reprodução de estratificações sociais com base na perpetuação de um ensino impositivo tanto no ambiente familiar quanto escolar, busca-se elaborar uma conexão deste "modelo reprodutor" sugerido pelo autor com as teorias foucaultinas de governabilidade e disciplina

\footnotetext{
1 Doutorado em Altos Estudos Contemporâneos (Ciência Política, História Contemporânea e Estudos Internacionais Comparativos) pela Universidade de Coimbra (Portugal). Professor do Departamento de Direito Penale Processo Penal, bem como do Departamento de Propedêutica Jurídica da Faculdade de de Direito da PUCRS e pesquisador convidado do CEIS 20 (Centro de Estudos Interdisciplinares do Século XX) da Universidade de Coimbra. E-mail: guto_jobim@hotmail.com

${ }^{2}$ Professora na Universidade do Vale do Itajaí (UNIVALI). Doutoranda no Programa de Pós-Graduação em Ciências Criminais da PUC/RS. Integrante dos Projetos de Pesquisa CNPq; Criminologia, Cultura Punitiva e Crítica Filosófica\&quot; (PUCRS); As
} 
desenvolvidos pelas instituições sociais e políticas, presente entre elas o próprio ensino.

É diante dos discursos vigentes que Foucault e Bourdieu se encontram para esclarecer que através do processo de ensino-aprendizagem se reproduzem estratificações sociais e dominação, não somente dominações institucionalizadas, mas também aquelas exercidas pelas próprias relações entre professores e alunos, representando os primeiros a autoridade pedagógica socialmente determinada para exercer a imposição dogmática através de uma falsa interação neutramente comunicativa. (BOURDIEU, 2011)

É determinado por Foucault que os micro poderes presentes na sociedade tratam-se de relações de forças múltipas que existem e encontram-se sempre em tensa atividade e que essas relações não são unicamente impostas pelo Estado ou suas instituições, mas que traduzem e existem a partir das relações propriamente ditas, pois para o autor o poder nada mais é que um exercício constante. (FOUCAULT, 2008)

Assim, através do exercício constante do poder que estabelecem as relações de poder apresentadas por Foucault, que o presente trabalho se propõe a vincular a prática pedagógica ao poder disciplinar reprodutor de uma dominação, utilizando como referências principais a análise da Escola como método disciplinar (FOUCAULT, 2007) e a abordagem de Bourdieu no que tange a escola como perpetuador de classe social (2011).

\section{AS CONDIÇÕES DE POSSIBILIDADE DO CONHECIMENTO NO MUNDO MODERNO}

As mudanças significativas na sociedade contemporânea, talvez iniciadas a partir de Einstein e sua teoria da relatividade (1905), colocam em posição desconfortável uma série de crenças que, outrora, acreditavam-se imortais. Quiçá com o choque das guerras mundiais percebeu-se que a técnica e a ciência não servem somente para a evolução da espécie humana. A máscara caiu: o projeto moderno da salvação está em crise.

Isto permite demonstrar, mesmo que de forma sucinta, a crise em que a ciência moderna está inserida. Junto dessa crise, coloca-se sob suspeita também todo o conhecimento produzido desde o século XVI até o presente momento. Os pensadores modernos acreditavam no progresso, na promessa $^{3}$, e, a partir disto, passaram a priorizar a vida e a pensar no futuro, ao contrário do que se vivia no período medieval, quando toda uma vida de sacrifícios se justificava em virtude do que viria após a morte: vivia-se para Deus, para a morte.

Não é demais recordar que toda a civilização ocidental foi afetada pela crença na ciência moderna: desde

Fronteiras entre Tradição e Modernidade na Construção do Estado Brasileiro; (PUCRS) e Bases para uma Criminologia do controle penal no Brasil: em busca da brasilidade criminológica (UFSC). Bolsista CAPES. E-mail: fernanda.ma@gmail.com 
que Descartes, com seu racionalismo (GAUER, 2001, p. 105), começou a questionar as formas de ver o mundo impostas pela Igreja Católica (fruto da oficialização dessa religião pelo Estado ${ }^{4}$ por volta do século IV), o mundo não é mais o que era antes: o filósofo francês deu impulso a uma nova visão de mundo para o homem, possibilitando a substituição do modelo teocêntrico pelo modelo antropocêntrico de explicar as coisas.

Todo conhecimento passa para a ordem da racionalidade, ou seja, o que não poderia ser racionalmente (cientificamente) explicado perdia todo valor como objeto de estudo e acabava se tornando invisível para o mundo da ciência. Podendo-se ver em Galileu o pai da ciência moderna, a meta em geral era dissolver os mitos e substituir a revelação pelo saber. Tais fenômenos, agora, poderiam ser previsíveis e controláveis, o que permitia ao homem estabelecer as leis da natureza. Sendo a natureza um objeto do conhecimento científico, ela poderia ser utilizada como instrumento de melhora da vida humana no mundo. Ao invés da contemplação, importava agora a intervenção e domesticação da natureza para melhorar as condições de vida. (GAUER, 2001, p. 102)

O pensamento moderno é, então, construído sob uma lógica de dominação, que possui como fundamento o esclarecimento, o conhecimento, a razão, e a melhora da vida no mundo em detrimento da ilusão, dos mitos, da fé, da crença, da metafísica, produzidos fundamentalmente pela Igreja.

Antes da revelação cartesiana,, "o universo medieval era finito, esférico e hierarquizado; esse universo morreu, e, com ele, a 'consciência' medieval de um 'mundo fechado'. A ruptura criada por Galileu contrapôs-se a esse mundo; sua teoria criou um universo 'infinito' e, portanto, 'aberto'. A dimensão religiosa do saber medieval foi quebrada. Na 'nova' visão, houve a separação entre razão e fé; a verdade reveladora não podia mais ser confundida com a ciência. O 'finito', ao ser substituído pelo 'infinito', subverteu a ordem de se pensar o mundo. O homem vive em um mundo onde ele não é o centro, o céu abriga inúmeros mundos, e o lugar do homem no mundo passou a ser questionado. Os espaços sagrados passaram também a ser questionados. A geometria de Galileu eliminou os espaços heterogêneos (céu-inferno) e criou espaços homogêneos, despojados de qualidades e passíveis de serem quantificados, mensurados, enquanto uma nova geometria espacial. Podemos arriscar dizer que Galileu criou a gênese do espaço democrático, uma vez que para ele todos os espaços se equivalem." (GAUER, 2001, p. 105-106)

Um determinismo rigoroso consolidou-se na visão que se tinha do mundo, e tudo era passível de explicação através da noção de causa-e-efeito. (CAPRA, 1983, p. 5) A base filosófica originou-se a partir da divisão entre res cogitans e res extensa, realizada por Descartes: acreditava-se ser possível explicar o mundo sem qualquer influência do observador humano, de forma objetiva e universal. (CAPRA, 1983, p. 52-56)

\footnotetext{
${ }^{3}$ Tomamos o termo promessa no sentido de vínculo com o futuro, uma certeza de que o futuro será melhor que o presente se cumprida essa promessa. Para maiores detalhes, conferir OST, François. O Tempo do Direito. Lisboa: Piaget, 1999.

${ }^{4}$ Note-se que o termo Estado, aqui, não deve ser conceituado da mesma forma como o é hoje, em virtude da separação temporal de mais de quinze séculos entre o século $V$ e os dias atuais.

${ }^{5}$ Expressão utilizada por Fritjof CAPRA, em O Ponto de Mutação, especialmente nas pp. 52-56.
} 
Essa cosmovisão mecanicista "foi sustentada por Isaac Newton, que elaborou sua Mecânica a partir de tais fundamentos, tornando-a o alicerce da Física clássica. Da segunda metade do século XVII até o fim do século XIX, o modelo mecanicista newtoniano do universo dominou todo o pensamento científico." (CAPRA, 1995, p. 25)

Toda essa construção do pensamento e do conhecimento moderno instaurou uma concepção de busca pela "verdade de todas as coisaš. Conforme Ricardo Timm de Souza, "o ser humano acabou por fazer da ciência a sua verdade racional, tendendo, especialmente na cultura ocidental, a fazer dela o seu ídolo ao qual tudo mais especialmente outras formas de racionalidade - é sacrificado."(SOUZA, 2004, p. 34) Além da explicação dos fenômenos, pretende a Ciência ser interpretação do mundo. E mais: a única interpretação verdadeira do mundo.

\section{A REPRODUÇÃO DA ORDEM}

Pierre Bourdieu e Jean-Claude Passeron em "A Reprodução" desenvolvem inicialmente a teoria da violência simbólica como mecanismo de seletividade das relações de poderes ou forças presentes no âmbito educacional. É formulada, pelos autores, a ideia de ação pedagógica como um processo impositivo de significações, imposto por um poder arbitrário, no qual o principal foco da referida ação se trata de inculcar no indivíduo submetido ao trabalho pedagógico o chamado habitus, cujo significado é um "produto da interiorização dos princípios de um arbitrário cultural capaz de perpetuar-se após a cessação da ação pedagógica e por isso perpetuar nas práticas os princípios do arbitrário interiorizado" (BOURDIEU; PASSERON, 2011, p. 53). Tratase, portanto, de um processo que atravessa as concepções de verdade que a modernidade propõe ao conhecimento.

Nesse sentido, para compreender as ideias de Passeron e Bourdieu faz-se necessário consagrar alguns conceitos por eles utilizados que permeiam a discussão da manutenção da ordem através da prática pedagógica. Os conceitos chaves utilizados pelos referidos autores que merecem atenção conceitual são ação pedagógica, autoridade pedagógica, trabalho pedagógico, autoridade escolar, sistema de ensino e trabalho escolar. Estes termos perpassam pela linha de pensamento dos autores na construção de sua teoria, estando todos interligados na consagração da identificação de estratificação social como resultado de um habitus e da seleção e imposição dos conteúdos pelos agentes pedagógicos.

Identifica-se então que ação pedagógica nada mais é que o próprio ato de ensino, que abordado pelos autores supracitados fica evidenciado como um ensino que pode ser exercido pelos os membros educados de uma formação social, cuja educação se chama difusa, ou pelos membros dos grupos familiares, chamando-se de educação familiar (BOURDIEU; PASSERON, 2011, p. 26). 
A partir destes grupos que formam os ramos de educação do sujeito, surge a figura da autoridade pedagógica, figura sobre a qual recai a autoridade legitimada pelos grupos como responsável pelos processos de seleção dos conteúdos e transmissão dos mesmos, ou como explicitado pelos autores, as autoridades pedagógicas "são logo de imediato designados de transmitir o que transmitem, e por conseguinte autorizados a impor a recepção e a controlar a inculcação por sanções socialmente aprovadas ou garantidas" (BOURDIEU; PASSERON, 2011, p. 42). Já o trabalho pedagógico é este processo de inculcação arbitrária da autoridade pedagógica cuja duração deve ser longa o bastante para produzir uma formação durável, o chamado habitus. (BOURDIEU; PASSERON, 201 1, p. 53). Ou seja, o habitus vem como um resultado das manobras impositivas e das relações de forças e de poder que permeiam a educação, sendo um resultado do referido trabalho pedagógico, definido pelos autores como:

enquanto trabalho prolongado de inculcação que produz um habitus durável e transponível, isto é, inculcando ao conjunto dos destinatários legítimos um sistema de esquemas de percepção, de pensamento, de apreciação e de ação (parcial ou totalmente idênticos), o trabalho pedagógico contribui para produzir e para reproduzir a integração intelectual e a integração moral do grupo ou da classe em nome dos quais ele exerce. (2011, p. 57)

Faz-se evidente o entendimento dos autores de que o trabalho pedagógico é a chave para o sucesso das práticas de reprodução, visto que é a partir deste que se aplicam os métodos pedagógicos de dominação. Neste sentido pode-se evidenciar que um trabalho pedagógico eficaz se dá quando do processo bem sucedido de inculcação de um habitus que façam esquecer os fundamentos arbitrários da cultura dominante e vise manter a ordem e reproduzir as estruturas das relações de força dos grupos dominantes (ROSENDO, 2009, p. 10).

Já o trabalho escolar pode ser entendido como um mecanismo utilizado pelo sistema de ensino institucionalizado pelo trabalho pedagógico que tem por objetivo o controle e a homogeneização do referido sistema, de forma que o habitus dos receptores sejam uniformes e devidamente dominados. Assim, o sistema de ensino pode ser percebido como um meio institucionalizado de produção e reprodução de um arbitrário cultural, do qual este sistema não é o produtor e cuja reprodução deste contribui para a reprodução das relações entre grupos e classes, a chamada reprodução social (BOURDIEU; PASSERON, 2011, p. 76 - 77). Os autores evidenciam-no da seguinte forma:

Todo sistema de ensino deve as características específicas de sua estrutura e de seu funcionamento ao fato de que lhe é preciso produzir e reproduzir, pelos meio próprios da instituição, as condições institucionais cuja existência e persistência (autoreprodução da instituição) são necessários tanto ao exercício de sua função própria de inculcação quanto à realização de sua função de reprodução de um arbitrário cultural do qual ele não é o produtor (reprodução cultural) e cuja reprodução contribui à reprodução das relações entre os grupos e as classes (reprodução social). (2011, p. 76 - 77)

Devidamente conceituados os principais símbolos de dominação e reprodução apresentados por Bourdieu, fica possível desenvolver a elaboração teórica que atravessa a percepção dos autores sobre a reprodução 
do habitusinculcado mediante as práticas de ensino (escolares e familiares) e as classes de origem.

A obra A Reprodução segue no sentido de demonstrar que todos esses instrumentos do processo de ensino são necessários para manter a ordem e a conservação social das classes dominantes e dominadas, assim como para estabelecer um convencimento do indivíduo de que o mesmo pertence a um lugar natural do qual este é proveniente e de que a escolha do seu destino se deve exclusivamente ao poder disciplinar da escola. Em suma, a escola utiliza-se de mecanismos de convencimento que determinam reproduções sociais e consolida estruturas de poder.

O sucesso desse instrumento moderno de poder se deve às ações pedagógicas excludentes que permitem uma relação de convencimento da ditadura da meritocracia como fator determinante das conquistas dos indivíduos e dos seus destinos (BOURDIEU; PASSERON, 2011, p. 249).

\section{A VALIDADE DO DISCURSO}

Foucault ao identificar osucesso disciplinar das instituições de dominação se questiona: "em uma sociedade como a nossa, que tipo de poder é capaz de produzir discursos de verdade dotados de efeitos tão poderosos?" (2008, p. 179).

Ao desenvolver a ideia de escola e ensino como instrumentos de reprodução e de dominação se faz necessário evidenciar as pesquisas de Foucault que desenvolvem a teoria do poder disciplinar como um mecanismo de captura e de dominação do corpo que tem por objetivo a obediência e a utilidade do mesmo (FOUCAULT, 2007, p. 118).

A partir da perspectiva de que a disciplina constrói um sujeito dócil "que pode ser utilizado, que pode ser transformado e aperfeiçoado" (FOUCAULT, 2007, p. 118), Foucault elabora o seu pensamento elencando as instituições que foram e são responsáveis pelo processo de disciplinamento dos sujeitos. A escola, assim, vem consolidar a disciplina no processo de ensino e de desenvolvimento do indivíduo, se tornando, então, uma instituição com poder capaz de (re)produzir discursos de verdade dotados de efeitos poderosíssimos.

Os discursos como veículo de imposição do ensino são bem apresentados pelo autor como produtos de interdições e restrições, as quais evidenciam as ordens determinantes por trás daqueles que falam e daqueles que selecionam o que deve ser falado, ora, a ação pedagógica.

Para Foucault certos discursos podem até transparecer uma inocência, todavia, estes podem ser descobertos em sua percepção nua quando encontradas as suas "interdições" (FOUCAULT, 1996, p. 10), pois são estas que revelam quem está sob controle e quais as relações de poder e de desejo que estão presentes no que é escrito e no que é falado. Tais interdições tratam daquilo que é permitido e do que é proibido se pronunciar num 
discurso institucional (MARTINS, 2008, p. 44).

O já referido autor expõe de maneira brilhante ao que se refere à rede de discursos, afirmando que:

(...) em toda sociedade a produção do discurso é ao mesmo tempo controlada, selecionada, organizada e redistribuída por certo número de procedimentos que tem por função conjurar seus poderes e perigos, dominar seu acontecimento aleatório, esquivar sua pesada e temível materialidade.

Em uma sociedade como a que nós conhecemos, é certo, há procedimentos de exclusão. $\mathrm{O}$ mais evidente, o mais familiar também a interdição. (1996, p.9)

É necessário, então, quando se busca tratar com discursos, perceber qual a ordem vigente presente nas entrelinhas daquilo que está sendo observado, qual o foco de eliminação ou manipulação do que se expõe, quais são os objetivos de haver uma sonegação de informação ou de criar uma perspectiva que conduza para uma determinada linha de pensamento, já que o "discurso não é simplesmente aquilo que traduz as lutas ou os sistemas de dominação, mas aquilo por que, pelo que se luta, o poder do qual nos queremos apoderar." (FOUCAULT, 1996, p. 10)

As relações de discurso estão diretamente envolvidas com a construção da ação e do trabalho pedagógico propostos por Bourdieu e Passeron, visto que as "relações de poder, exercitadas na relação pedagógica, atravessam a escola e fazem parte do discurso de sala de aula, gerando saberes e poderes nas interações entre professores e alunos" (AQUINO, p. 22).

A clara relação existente entre a força do discurso e a ação pedagógica se dá na construção de verdades e do poder simbólico relacionado a tal ato. Para Foucault o regime da verdade está diretamente relacionado à apropriação do local da fala como transmissão de uma verdade inquestionável (FOUCAULT, 2008), enquanto que em Bourdieu a violência simbólica é o que permite a autoridade pedagógica de usar do local da fala como espaço de dominação (BOURDIEU; PASSERON, 2011). Bourdieu afirma que o "professor deve ser dotado pela instituição dos atributos simbólicos da autoridade ligada a seu cargo (a começar pela 'farda do discurso' [...] )" (2011, p. 160). Já Foucault evidencia que o problema intelectual se apresenta através desta verdade, a qual está ligada a "sistemas de poder, que a produzem e apóiam, e a efeitos de poder que ela induz e que a reproduzem" (2008, p. 14), sendo o ambiente escolar um disseminador da verdade autorizada.

Contudo, os autores efetivamente assemelham-se quando Foucault explora a apropriação do corpo e o disciplinamento deste como mecanismo de dominação, e Bourdieu, na sua análise sobre a ação escolar e os agentes pedagógicos, evidencia a figura do docente e da instituição escolar como instrumentos a serviço do sistema reprodutor. 


\section{O PODER DISCIPLINAR COMO MÉTODO DE REPRODUÇÃO}

A relação que envolve o pensamento de Bourdieu e Foucault encontra seu ponto crucial na manifestação do poder disciplinar das instituições (FOUCAULT, 2007), cujo mecanismo chave para tal procedimento pode ser entendido como a figura da ação pedagógica, a qual se torna válida e eficaz através do trabalho pedagógico.

O uso do corpo como instrumento de dominação, compreendido por Foucault como poder disciplinar, é demonstrado a partir das diversas formas das instituições se apropriarem dos sujeitos através da coordenação dos seus atos, mais propriamente dos corpos destes indivíduos. Pode ser entendida tal política de apropriação em função da ordem como uma "política das coerções que são um trabalho sobre o corpo, uma manipulação calculada de seus elementos, de seus gestos, de seus comportamentos." (FOUCAULT, 2007, p. 119)

A título de poder disciplinar, o autor em questão aborda não somente a escola como instituição de dominação e reprodução, mas também evidencia as prisões, os hospitais e o exército como espaços de controle corporal dos indivíduos como mecanismos de controle da ordem.

Nestes ambientes se constrõem a "organização do espaço serial" (FOUCAULT, 2007, p. 126), onde através da individualização dos lugares e dos trabalhos atribuídos aos sujeitos individualmente se torna possível "vigiar, hierarquizar e recompensar" (FOUCAULT, 2007, p. 126) cada sujeito pelo cumprimento das atividades cabidas a ele. É relatado por Foucault que a ordenação dos sujeitos por filas se desenvolve a partir do século XVIII, e tem como objetivo definir a posição das pessoas nestes espaços institucionais, mais propriamente, no âmbito escolar (FOUCAULT, 2007, p. 125), desenvolvendo uma ordem hierarquizada e controlada, na qual o professor possui a significativa função de garantidor da ordem e da obediência dos indivíduos.

Este procedimento, então, só é possível de ser realizado eficazmente se houver uma figura autoritária que determine as funções de cada sujeito e inculque a disciplina como um ato habitual e sobre o qual não haverá questionamentos. A conquista de disciplinar passa pelo entendimento do professor como sujeito legítimo para cumprir tal função e pela prática constante e repetitiva do trabalho escolar como forma de atribuir às práticas pedagógicas um sentido que satisfaça o sujeito (BOURDIEU; PASSERON, 2011, p. 43). A política de ensino como formação de habitus é o ato de maior violência e a autoridade mais evidente que se entrega ao professor, visto que é através da construção de uma habitualidade, de uma prática "habitual" que se conforma o sujeito à reprodução e à sua dominação.

A hierarquia e a dominação do conhecimento se completam como um método de legitimação dos professores e das escolas como responsáveis pela seleção dos indivíduos capazes de avançarem, permanecerem ou regredirem no que tange os estratos escolares, assim como, os sociais. Para Bourdieu o

culto da hierarquia, puramente escolar na aparência, contribui sempre para a defesa e 
legitimação das hierarquias sociais na medida que as hierarquias escolares, quer se trate de hierarquia dos graus dos títulos ou da hierarquia dos estabelecimentos e das disciplinas devem sempre alguma coisa às hierarquias sociais que elas tendem a reproduzir (BOURDIEU; PASSERON, 2011, p. 186).

A legitimidade do discurso proferido pelo professor e pela instituição é proveniente de diversas categorias que identificam a classe social do sujeito e utilizam-na como mecanismo de controle (BOURIDEU; PASSERON, 2011, p. 42). É uma referência à legitimação da figura da autoridade pedagógica a autoridade da linguagem, onde o diálogo travado entre alunos e professores se estabelece como um discurso falacioso, no qual o mestre transmite palavras inacessíveis aos alunos, como maneira de segregação e autoafirmação. (BOURDIEU; PASSERON, 201 1, p. 136 - 138). Neste sentido Bourdieu e Passeron expõem que

reduzir a relação pedagógica a uma pura relação de comunicação seria impedir-se de perceber as características específicas que ela deve à autoridade da instituição pedagógica: só o fato de transmitir uma mensagem numa definição social (tanto mais explícita e codificada quanto essa conexão é mais institucionalizada) do que merece ser transmitido, do código no qual a mensagem deve ser transmitida, dos que têm o direito de transmiti-la ou, melhor, de impor a recepção, dos que são dignos de recebê-la e, enfim, do modo de imposição e de inculcação da mensagem, que confere a legitimidade e, através disso, o sentido completo à informação transmitida. (2011, p. 137 - 138)

A relação com a linguística é uma forma de definir a classe social de origem do aluno, na qual a bagagem cultural resultante do trabalho pedagógico primário, ou familiar, definirá o habitus do indivíduo quando este ingressar no âmbito escolar e determinará a aproximação deste com a fala articulada pelos professores. (BOURIDEU; PASSERON, 2011, p. 71)

Essa articulação entre o trabalho pedagógico primário e secundário (escolar) é o determinante para desenvolver a continuidade de dominação das classes dominantes sobre os demais, sendo que será mais bem articulada a continuidade dos trabalhos pedagógicos reprodutores quão melhor tiver sido o processo de inculcação do habitus no sujeito, já no trabalho pedagógico primário (BOURDIEU; PASSERON, 2011, p. 73). Bourdieu desenvolve claramente o seu pensamento sobre tal procedimento quando afirma que

o trabalho pedagógico secundário dominante que recorre a um modo de inculcação tradicional [...] tem uma produtividade específica tanto mais fraca quanto mais se exerce sobre os grupos ou classes formadas por um trabalho pedagógico primário mais afastado do trabalho pedagógico primário dominante, que inculca, entre outras coisas, um domínio prático com uma dominante verbal, tal trabalho pedagógico tende a produzir, em e por seu próprio exercício, a delimitação de seus destinatários realmente possíveis, excluindo tanto mais rapidamente os diferentes grupos ou classes quanto estão mais completamente desprovidos do capital e do ethos objetivamente pressupostos por seus modo de inculcação. (2011,p. 73)

A partir da relação dos trabalhos pedagógicos primário e secundário, o professor recebe o indivíduo com a clara função de transmitir um conhecimento selecionado e reprodutor, no qual existe a ilusão de que o ensino repassado se dará através da neutralidade do sistema de ensino, todavia, é visto que tanto o conhecimento quanto o discurso neutro são falácias que garantem a continuidade do método da neutralidade como mecanismo de 
reprodução. (BOURDIEU; PASSERON, 2011, p. 90) Em suma, não existe comunicação neutra, visto que o diálogo entre professores e alunos é dotado de uma linguagem magistral, cuja função é determinante para legitimar a autoridade pedagógica, sendo que é através da distância que existe entre o conhecimento cultural de cada classe ou grupo social, proveniente do trabalho pedagógico primário, que se pode determinar o entendimento que os alunos de classes sociais diversas terão sobre a mesma exposição efetuada pelo professor.

A relação de reprodução e de dominação que se constrói por meio do sistema de ensino é bem explicitada por Foucault através da sua teoria de construção dos dispositivos de disciplinamento instituídos a partir do século XVIII, como procedimentos de apropriação do corpo com fim único de utilizá-lo a reproduzir as relações de poder vigentes.

Bourdieu e Foucault se comunicam, então, quando discutem as formas de reprodução social e cultural pela qual a escola, como instituição oficial, é responsável. O diálogo se dá no sentido de que o discurso proveniente do sistema de ensino trata-se de um discurso construído e instituído pelas classes ou grupos dominantes e de que a seleção, considerada meritocrática, nada mais é que uma seleção excludente daqueles que desde o início do processo de aprendizagem estiveram distantes dos grupos de dominação. Ainda, é relevante destacar que não somente, quando a partir de Foucault, o processo de governabilidade se opera através de estruturas e estratos, mas se permeia por todas as redes que operam o processo de ensino.

\section{AINDA ASSIM, OCORRE O OUTRO: ÉTICA DO AGIR HUMANO E A NEGAÇÃO DA VIOLÊNCIA DO MONÓLOGO}

Nesse sentido, a lógica da exclusão-marginalização, da submissão do aprendiz aos dizeres do mestre adepto do método puramente expositivo, portanto, excludente "onde o professor raciocina unilateralmente em voz alta, (...), aponta a solução 'única', 'definitiva' e 'verdadeira', num atentado à inteligência e capacidade dos estudantes" (MELO FILHO, 1985, p. 115) acaba por transformar o aluno em mero objeto do processo de aprendizagem, usurpando-lhe a possibilidade de estabelecer um diálogo frutífero com o professor e seus colegas.

O Outro levinasiano ${ }^{6}$ parece não se fazer presente na relação professor-aprendiz, onde o professor

\footnotetext{
${ }^{6}$ Não existe questão humana que não seja uma questão radicalmente ética. Portanto, contar com a alteridade e tê-la em conta representa o intervalo crítico que, irredutível à tematização, convoca a diferença como significação para além de qualquer essência. O trauma ao pensamento logocentrado inspira um instante que irrompe no dizer ético por excelência, desagregando, com seu encontro com o outro, as racionalidades bem pensadas e que investe de responsabilidade qualquer crítica da realidade. Assim será menos difícil captar a sutileza que é título da obra mais importante de Emmanuel Levinas: "de outro modo que ser, ou mais além da essência” (1978). A palavra quejá traz a ruptura do modo de pensar ontologizante, pois não visa um outro modo deser, mas sim um ou modo de pensar que vá além do que o modo de pensar do ser. Um outro ponto de partida. Uma notória an-arquia na formatação do pensamento ocidental. Levinas esclarece, ao comentar essa obra, que o des-inter-esseé o que quer dizer o título do livro "de outro modo que ser". A condição ontológica desfaz-se, ou é desfeita, na condição ou incondição humana. Ser humano
} 
representa o Eu e o aprendiz, o Outro. Onde sempre esteve este Outro? Para onde foi levado? A que condição Ele foi relegado ao longo de todos esses anos? A responsabilidade do Eu em relação ao Outro, até então, aparenta nunca ter existido.

Nada mais propício que se pensar essa relação do mestre com seus aprendizes, desde há muito relegados à condição de não-ser. $\mathrm{O}$ modelo supra mencionado das aulas magistrais ignora a alteridade, subtrai do aprendiz a oportunidade de se estabelecer e reconhecer como ser, como sujeito. Asseveram Jacques Delors et al. que "os métodos de ensino não devem ir contra este reconhecimento do outro. Os professores que, por dogmatismo, matam a curiosidade ou o espírito crítico dos seus alunos, em vez de os desenvolver, podem ser mais prejudiciais do que úteis." (DELORS, 1998, p. 98)

Um modelo que, ao atribuir ao professor toda a responsabilidade pelo ensino, não poderia deixar de estar em crise - muito embora essa crise não dê sinais de quando, efetivamente, teve início. Nada de novo se aduz, portanto, aqui. Apenas deve-se continuar no caminho do questionamento das práticas de ensino que ignoram a alteridade como condição fundamental para que haja uma troca recíproca entre mestre e aprendiz, deixando para trás o monólogo dos professores e estabelecendo uma dinâmica de interação com seus aprendizes.

Degenerou-se algo que é eminentemente anterior ao contato professor-aluno: a própria relação humana "saudável". O que se amplia enormemente é uma razão puramente instrumental tendente a formatar, enquadrar, formalizar o "informalizável", ou seja, o sentido do contato humano que se deve ter como primordial. Neste diapasão, não há possibilidade de encontro enquanto local de irrupção do novo, de ruptura; apenas afirma-se a identidade em desfavor da diferença.

Na reprodução deste micro-cosmo democrático que é o processo de "do-discência" (FREIRE, 2005, p. 23-51), o diálogo educacional implica enfim a sua fundação numa norma ética de exercício em favor do Outro. A eticidade como fundamento primeiro do convívio humano se impõe à prática educativa, sob pena de perder sua razão de ser. Por certo, não se pretende chancelar o discurso pondo a ética como fundamento, exercendo-a como uma potência auto-explicativa. Avesso à banalização e à manipulação conceitual, pretende-se colocar a ética como

significa: viver como se não fosse um ser entre os seres. Como se, pela espiritualidade humana, invertessem-se as categorias do ser, num "de outro modo que ser". Não apenas num "ser de modo diferente; ser diferente é ainda ser" (1999, p. 93). Conforme Ricardo Timm de Souza (1999, p. 151): "A verdade do não-ser não é menos verdadeira e importante do que a verdade do ser, somente porque seu "conteúdo de verdade" - sua Alteridade - não pôde conservar sua dimensão própria e teve de entregá-la à determinação da Totalidade. A verdade do Outro-que-ser é uma outra verdade, que não tem seus alicerces na dinâmica da liberdade do ser." Enquanto para Heidegger a história da filosofia está no esquecimento do Ser, para Levinas o limiar da crise não está propriamente no esquecimento da diferença ontológica entre ser e ente. "A problematização se insere a partir do esquecimento do 'outro' como foco de responsabilidade do mesmo. Inverte-se a lógica do que significa pensamento. "Pensar não é mais contemplar, mas engajar-se, estar englobado no que se pensa, estar embarcado - acontecimento dramático do ser-no-mundo." (LEVINAS, 1997, p.23). Ultrapassar as barreiras de uma mera unidade psíquica solitária e monádica para uma dimensão de subjetividade que suporte o peso da decisão pelo outro é o que move Levinas a se perguntar se "a ontologia é fundamental?". 
a própria condição de possibilidade de pensar o humano. E é na especificidade do ato educacional que a situação toma contornos extremos.

As instituições educacionais demonstram que jamais podem por si construírem espontaneamente relações éticas necessárias. O que se desdobram são estruturas anti-humanas que olvidam a ética como crivo do sentido vital (SOUZA, 2004, p. 33). O sentido de vida toca a Ética como filosofia primeira no exame dos liames relacionais; longe, contudo, de neutralizações e equalizações de sistemas tautológicos.

Não se receia em dizer que a ética, neste sentido, está no centro do tema da educação, pois é reflexo da própria justiça, como anseio que é de qualquer pensar: ética como vontade de justiça em realização, justiça para com o "outro que nós" (SOUZA,2004, p. 51). Outro que é o meu interdito, limite da minha representação, o estrangeiro $^{8}$ que rompe com minha tautologia de ser e segurança de mundo, aquele que tem a sua verdade e desafia meu intelecto. Apenas posso ousar enunciá-lo exatamente por aquilo que ele se deixa determinar. Daí a consideração primeira pela nascente e irredutível diferença do outro, que dá expressão a uma não-indiferença ética.

Como estou disposto a ele e não posso explicá-lo, cabe relacionar-me com ele, a saber, uma racionalidade ética. O ético, assim exige um pensar (construir sentidos) a partir deste encontro, para além da dimensão lógica do 'logos'. "Se o mundo não é propriamente concebido e pensado desde princípios lógicos abstratos ou desde a articulação pura e simples de interesses de poder, e sim desde 'encontros humanos reais' em sua infinita variedade, isso significa algo para além das retóricas: significa que é possível a concepção de uma outra racionalidade em meio às já existentes - a racionalidade ética. Assim, (...) irracionais são, antes, as postulações de racionalidades que se promulgam únicas, ou unicamente legítimas ou possíveis, em meio à variedade extraordinária do mundo, dos mundos que se encontram." (SOUZA, 2004, p. 125)

Pensar a realidade educacional enquanto possibilidade de justiça (SOUZA, 2003, p. 619-633), é raciocinar a diferença nas diversas relações humanas desde uma assimetria, de uma diacronia irredutível. Falar de diferença é falar de justiça, e falar de justiça é falar do também irredutivelmente outro. Suma, o núcleo da diferença,

Percebe que partindo do ponto de vista ontológico como filosofia primeira, sempre compreender-se-á a ética como estilhaços do $\operatorname{ser}(1997$, p. 31).

${ }^{7}$ A ética como filosofia primeira significa: todo contato com a realidade, toda interpretação desta realidade e todas as possíveis interpretações destes fatos se dão eticamente, onde o contato e a ação éticos subsistem o conhecimento classificador tradicional e podem vir a fundamentar um conhecimento sobre bases absolutamente novas, com outro 'sentido'. Todo conhecimento é então necessariamente secundário a uma atitude ética primeva frente às mais diversas dimensões da realidade perceptível, a um nascimento compartilhado 'eticamente', talvez um retorno à origem da 'co-naissance'. SOUZA, Ricardo Timm de. Filosofia primeira e ética da produção, pp. 117-129

${ }^{8}$ A questão do estrangeiro é uma questão 'de' estrangeiro, uma questão vinda 'do' estrangeiro, e uma questão ao estrangeiro, dirigida 'ao' estrangeiro. Como se o estrangeiro fosse, primeiramente, 'aquele que' coloca a questão ou aquele que 'a quem' se endereça a primeira questão. Como se o estrangeiro fosse o ser-em-questão, a própria questão do ser-em-questão, o ser-questão ou o ser-em-questão da questão. DERRIDA, Jacques. Anne Dufourmantelle convida Jacques Derrida a falar Da Hospitalidade, p. 05. 
ou seja, a ética é o que é indesconstrutível de toda desconstrução, aquilo que a suporta.

Essa pré-condição da prática docente, que a antecede (visto que só pode existir prática docente com a presença dos aprendizes), se não for plenamente assumida pelos professores, possibilitará a sutil (porém marcante) manifestação da violência do monólogo acadêmico, sob pena de ser mantida a lógica da exclusão da racionalidade criativa e produtiva que todo ser humano possui.

\section{CONSIDERAÇÕES FINAIS}

Certa conexão possível que se pode atribuir ao que expõe tanto Bourdieu quanto Foucault é fundamentalmente unânime no que revela a escola e o sistema de ensino em si como mecanismos de reprodução de saberes das classes dominantes e como um espaço primordialmente seletivo e disciplinador da ordem vigente. Ao se questionar sobre a ruptura destas relações de poder que se consolidam através das instituições, entretanto, cada autor possui uma perspectiva diversa sobre a possibilidade de se desconstruir a dominação e a reprodução dos "mais fortes".

Esse monólogo acadêmico tende a se manter caso a alteridade não for assumida pelos docentes em relação aos seus aprendizes, contudo a possibilidade de se estabelecer um frutífero e criativo diálogo deve ser criada.

Entendemos ainda ser necessário ir mais além, assumindo também que, em pleno século XXI, não mais se deve ignorar a imperiosa superação das fronteiras limitativas das disciplinas, ampliando nossas formas e maneiras de raciocínio com o auxílio de outras áreas do conhecimento, tornando plena e efetiva a transdisciplinaridade nos bancos acadêmicos.

O significado de confluência de vários ramos do saber no estudo de terminada problemática gera o efeito desestabilizador tanto da dicotomia sujeito-objeto quanto à disciplina e suas especialidades. O método dialógico, segundo Edgar Morin (MORIN, 1999, p. 108 - 109), seria o ponto de partida na construção de um saber que ultrapasse a compreensão especializada da modernidade, uma vez que dispõe sobre a relação complexa entre compreensão e explicação. Assim, para a realização de uma análise que atenda minimamente à compreensão e debate do tema aposto, a limitação do poder punitivo estatal, como tal insuscetível de explicação satisfatória por uma única disciplina, por óbvio, faz-se imperativo ultrapassar o campo específico da ciência jurídica. Idéía esta que se aliará ao que Morin chama de inter-poli-transdisciplinariedade (MORIN, 2000, p.105-106), considerando-se o devido esclarecimento quanto à polissemia e imprecisões terminológicas extraíveis destas definições.

Frente à dinâmica complexa do social, impõe-se ao ensino uma postura de mesma dimensão. Um pensamento complexo, pois, corresponde ao próprio embaraço inerente à enfermidade congênita do 
conhecimento científico "ordenador". Palavra esta mesma - complexidade - que não pode se resumir em solução cognitiva ou chave do mundo, mas apenas no início de maiores desafios e problematizações (MORIN, 2003, p. 11).

Se o aprendizado "implica o abandono dos marcos de segurança que nos limitam na direção da compreensão dos novos movimentos da vida,"(PÔRTO, 2003, p. 100) trazemos novamente Edgar Morin, que lembra que "Marcel Proust [já] dizia: 'Uma verdadeira viagem de descobrimento não é encontrar novas terras, mas ter um olhar novo'."(MORIN, 2000 ,p. 107) Perceber os novos movimentos da vida a partir de um novo olhar apresenta-se como crucial nesse contexto, podendo-se pensar que essa postura inovadora propicia um estímulo à criatividade dos aprendizes, já que ela "não é paralisante frente ao deslumbramento: é motivadora da ação, do engajamento para transformação do mundo." (PÔRTO, 2003, p. 102)

A inovação, na esteira de Délcia Enricone, "pode modificar concepções curriculares, disciplinas, avaliação, aprendizagem do aluno e formas de ensinar e aprender." (ENRICONE, 2004, p. 53) O abandono da limitada zona da certeza tradicional do espaço de ensino, por um lado, sujeita "ao perigo de contornos indefinidos e de noções equívocas, mas, de outro, com a vantagem de poder atualizar-se e libertar-se de seu conhecido ranço," (MELO FILHO, 2000, p. 123) desafia o aprendiz a raciocinar a partir das incertezas, do novo, do desconhecido, estimulando seu senso crítico e, conseqüentemente, sua criatividade. A função da escola deveria ser justamente esta, de "modificar o conhecimento cotidiano, no sentido de torná-lo mais complexo, buscando as articulações e as interdependências entre os conhecimentos, propondo uma visão mais crítica de mundo." (ENRICONE, 2004, p. 47)

Deixar de lado a condição de sujeito dos aprendizes e ignorar a transdisciplinaridade no ensino jurídico significa deixar tudo como sempre foi e manter a antiga sistemática dentro das salas de aula. O fenômeno jurídico não pode ser explicado somente através de leis, ordenamentos e doutrinas jurídicas, devendo deixar-se trabalhar pelos outros campos do saber, reconhecendo suas múltiplas faces e possibilidades de entendimento.

E, dentro desse contexto, nada mais natural que os aprendizes possam dialogar com seus mestres, de forma a trabalhar melhor sua criatividade e exercê-la cotidianamente, a partir de uma postura produtiva, e não simplesmente reprodutiva.

\section{REPRODUCTIVE RELATIONSHIPS IN THE TEACHING PROCESS}

\section{Abstract}

The reflections that will be developed in this text seek to highlight the power relations and domination as mechanisms of social reproduction in the teaching areas. It still intends to present a possible posture for the 
educational practice that questions the old methods of teaching from its epistemological bases. Thus, based on Bourdieu's theories on the reproduction of social stratification based on the perpetuation of a tax education in both the family and the school environment, it is sought to elaborate a connection of this "reproductive model" suggested by the author with the Foucauldian theories of governability and discipline developed by social and political institutions, present among them the teaching itself. It is judged, that way. As a condition of possibility for the adoption of this new posture respect for the Other, through the ethics of otherness, and in the context of the debate about the failure of academic monologues.

Keywords: Teaching; Reproduction; Domination.

\section{REFERÊNCIAS}

AQUINO, Miriam de Albuquerque. Relações de poder cercando a educação: uma visibilidade foucaultiana. João Pessoa, 2002.

BOURDIEU, Pierre; PASSERON, Jean-Claude. A reprodução: elementos para uma teoria do sistema de ensino. Petrópolis: Vozes, 2011.

CALLEWAERT, Gustave. Bourdieu, um crítico de Foucault. Educação, sociedade e cultura. n. 19, p. 131 - 170, 2003. Disponível de http://www.fpce.up.pt/ciie/revistaesc/ESC19/19-5.pdf

CAPRA, Fritjof. O Ponto de Mutação. 14. ed. São Paulo: Cultrix, 1995.

1983.

O Tao da Física. Um paralelo entre a física moderna e o misticismo oriental. 27. ed. São Paulo: Cultrix,

CHARLOT, Bernard. A Escola e o trabalho dos alunos. Sísifo. Revista de Ciências da Educação, 10, pp. 89-96. St, Out, Nov, Dez 2009. Disponível em http://sisifo.fpce.ul.pt

DELORS, Jacques et al. Educação: um tesouro a descobrir. São Paulo: Cortez/UNESCO, 1998.

DERRIDA, Jacques. Anne Dufourmantelle convida Jacques Derrida a falar Da Hospitalidade. São Paulo: Escuta, 2003.

ENRICONE, Délcia. O Professor e as Inovações. In: ENRICONE, Délcia (org.). Ser Professor. 4. ed. Porto Alegre: EDIPUCRS, 2004.

FOUCAULT, Michel. Arqueologia do Saber. Rio de Janeiro: Forense Univesitárias, 2000.

Microfísica do poder. São Paulo: Ed. Graal, 2008.

A ordem do discurso. São Paulo: Ed. Loyola, 1996.

A verdade e as formas jurídicas. Rio de Janeiro: NAU Ed., 2003.

Vigiar e Punir: nascimento da prisão. Petrópolis: Vozes, 2007.

FREIRE, Paulo. Pedagogia do oprimido. Rio de Janeiro: Terra e Paz, 1983.

FREIRE, Paulo. Pedagogia da Autonomia: saberes necessários à prática educativa. 31. ed. São Paulo: Paz e 
Terra, 2005 .

GAUER, Ruth M. Chittó. A Construção do Estado-Nação no Brasil: a contribuição dos egressos de Coimbra. Curitiba: Juruá, 2001.

LEVINAS, Emmanuel. Autrement qu' être ou au-delà de l'essence. The Hague: Martinus Nijhoff, 1978.

Entre nós. Ensaios sobre a alteridade. Petrópolis: Vozes, 1997.

MARTINS, Fernanda. O feminino "criminoso": o discurso jurídico e a ordem criminológica no infanticídio. Revista Santa Catarina em História, v. 2, p. 39-48, 2008

MELO FILHO, Álvaro. Ensino e Raciocínio Jurídicos. In: Revista da Faculdade de Direito da Universidade Federal do Ceará, n. 25, v. 1. Fortaleza, 1985.

Metodologia Científica Aplicada ao Direito. In: Revista da Faculdade de Direito da Universidade Federal do Ceará, n. 26, v. 2. Fortaleza, 1985.

MORIN, Edgar. A Cabeça Bem-Feita: repensar a reforma, reformar o pensamento. 2. ed. Rio de Janeiro: Bertrand Brasil, 2000.

O método III. O conhecimento do conhecimento. Porto Alegre: Sulina, 1999.

Introdução do Pensamento Complexo. 4a ed. Lisboa: Piaget, 2003.

PÔRTO, Inês da Fonseca. Ensino Jurídico, Diálogos com a Imaginação: construção do projeto didático no ensino jurídico. Porto Alegre: S.A. Fabris, 2000.

SOUZA, Ricardo Timm de. A Racionalidade Ética como Fundamento de uma Sociedade Viável: reflexos sobre suas condições de possibilidade desde a crítica filosófica do fenômeno da 'corrupção. In A Qualidade do Tempo: Para Além das Aparências Históricas. GAUER, Ruth Maria Chittó (org.). Rio de Janeiro: Lumen Juris, 2004. 2004

Ética como Fundamento: uma introdução à ética contemporânea. São Leopoldo: Nova Harmonia,

Filosofia primeira e ética da produção. In Totalidade e Desagregação: sobre as fronteiras do pensamento e suas alternativas. Porto Alegre: EDIPUCRS, 1996.

Justiça, Liberdade e Alteridade Ética. In Justiça e Política: homenagem a Otfried Höffe. OLIVEIRA, Nythamar Fernandes de; SOUZA, Draiton Gonzaga de. Porto Alegre: EDIPUCRS, 2003.

Sujeito, ética e história. Levinas, o traumatismo infinito e a crítica da filosofia ocidental. Porto Alegre: Edipucrs, 1999.

VEIGA-NETO, Alfredo J. Foucault e educação: outros estudos foucaultianos. In: SILVA, Tomaz Tadeu da Silva (Org.). O sujeito da educação - estudos foucaultianos. São Paulo: 1995, p. 225 - 246.

Trabalho enviado em 08 de dezembro de 2017.

Aceito em 14 de março de 2018. 